\title{
THE FUTURE OF HEALTH COMMUNICATION INNOVATING THROUGH PARTNERSHIPS
}

\author{
SCOTT C. RATZAN
}

The Preamble of the Constitution of the World Health Organization reminds us that «Informed opinion and active cooperation on the part of the public are of the utmost importance in the improvement of the health of the people" (Grad, 2002). Nonetheless, nearly seven decades later, the conditions under which people can be informed and actively participate in their health management in a meaningful way are being globally challenged. Drawing from experience in a variety of areas that I will delve into in this article, I remain a believer that we can marshal the necessary forces to advance the communication of health issues and create a base for a health-literate population to make smart(er), healthier decisions that advance health and well-being.

Keywords: health communication, health literacy, Ebola, vaccines, innovation.

The ultimate goal of health communication is to advance an informed and empowered individual who can make smart choices for themselves, their families and communities whether it be in daily life, business and/or public policy. While the goal and practice may seem elusive, a simple fundamental tenet is that we need to advance our communication prowess to develop health literacy from individuals to the body politic. Ideally, an ethical, evidence-based communication approach can build upon historical challenges of how we address issues in science and health - from creationism to the heliocentric theory of the universe to nuclear physics to climate change. While Darwin, Galileo, Copernicus and others challenged the conventional wisdom and the «faith-based» approach of their time, countless others joined then and now in advancing science-based approaches to make the world a better place.

In this article I will draw from experience of some of the main areas where communication can make a difference in health: women and children's health, addressing infectious disease, health literacy with non-communicable disease, and finally by providing some high ideals for future ethical, evidence based health communication.

\section{WOMEN AND CHILDREN'S HEALTH}

I was fortunate to be able to play a major role in women and children's health as a founding co-chair of the United Nations Secretary General Innovation Working Group (IWG) along with Tore Godal, Special Adviser on Global Health to the Prime Minister of Norway. The IWG was convened by the United Nations Secretary General (UNSG) in 2010 to harness the power of costeffective innovation to accelerate progress towards achieving the health Millennium Development Goals. In support of the Global Strategy for Women's and Children's Health, the IWG serves as the global hub for innovation in the UNSG's Every Woman Every Child initiative. In contributing to improving women's and children's health,

the IWG catalyzes the initiative and enables the scaling of innovations across technological, social, financial, policy, and business domains. The IWG also pursues leadership by supporting collaborative efforts among mHealth [mobile health] stakeholders.

While I served as inaugural co-chair for the first three years, we established a proof of concept that in an IWG - a flexible structure and extensive network (with over 180 members representing over 
80 institutions) and specialized working groups - we made the case for innovation, whether scientific and technological, social, business, financial or some combination of these. Our first publication, Investing in our common future, brought thought-leaders' ideas in innovation and discussed how we can improve health literacy, develop and use new technologies such as mHealth, and innovate in the delivery of services through an array of public-private partnerships (World Health Organization [WHO], 2010). These articles were published on the World Health Organization website and helped form the idea for a Charter and organization of work streams.

The IWG produced practical reports on sustainable business models for delivering health care, an engagement guide for companies, checklists for improved health care, deploying innovative medical devices in low-resource settings, nutrition for adolescent girls, mHealth and Telemedicine, and innovative financial models. A unique feature in the design is that each report was led in an innovative non-prescriptive way with cochairs from different sectors.

For instance, the private sector, academic, country and NGOs all played roles in varied combinations. Each of the work-stream publications includes recommendations which have been integrated for scaling various UN and country activities.

For example, the IWG checklist task force report highlights the potential of checklists and scorecards for improving health literacy (Spector \& Ratzan, 2012) with some very basic ideas drawn from other fields. Checklists are a low-cost innovation with an increasingly large evidence base to address the management of complex or neglected tasks. Harvard School of Public Health professor Atul Gawande made groundbreaking strides in the use of checklists with his book, The checklist manifesto: How to get things right (2010). This evidence-based approach was based on a study (Pronovost et al., 2006) that found a five-item checklist could be used to reduce infection rates from intravenous catheters to zero, thereby saving $\$ 45,000$ per patient and avoiding 28,000 deaths in hospital intensive care units. Concomitant to our work at the IWG, The Lancet (2012) published an editorial that stated: «new frugal technologies do not have to be sophisticated gadgets, but can be as simple as a checklist».

\section{Five steps to prevent central line infections}

Wash hands using soap or alcohol prior to placing the catheter.

2 Wear sterile gloves, hat, mask and gown.
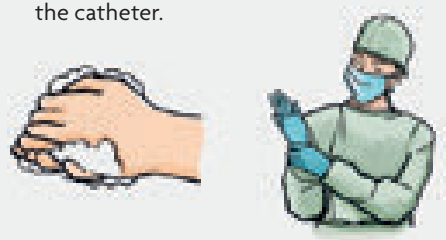

Completely cover the patient with sterile drapes. Avoid placing the catheter in the groin, if possible.

Clean the insertion site on the patient's skin with chlorhexidine antiseptic solution.

$\stackrel{\times}{>}$

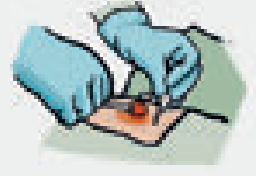

5 Remove catheters when they are no longer needed.

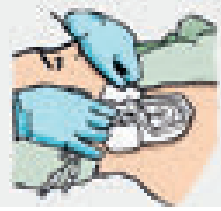

Checklists are a low-cost innovation with an increasingly large evidence base which can be used to address management of complex or neglected tasks.
The IWG identified opportunities for checklist programs that could bundle vital elements of existing guidelines into a simple, userfriendly format comprising actionable items. This included a number of recommendations, including how to effectively combine checklists with mobile technology (Spector \& Ratzan, 2012). The United Nations Commission on Life-Saving Commodities for Women and Children report integrated these ideas and scaled them globally:

Using checklists to help ensure that all critical steps associated with a specific health event (e.g., birth) are completed. Checklists not only work as a memory aid, particularly in time-sensitive situations, but also help to ensure that health-care workers are using the latest procedures.

(United Nations Population Fund, 2012)

\section{INFECTIOUS DISEASE: FROM EBOLA TO VACCINES}

The need for ethical communication for health has become particularly apparent in the recent Ebola crisis, which has been characterized by apocalyptic predictions of infection rates (over one million by the US Centres for Disease Control and Prevention), rumors, and widespread panic (Ratzan \& Moritsugu, 


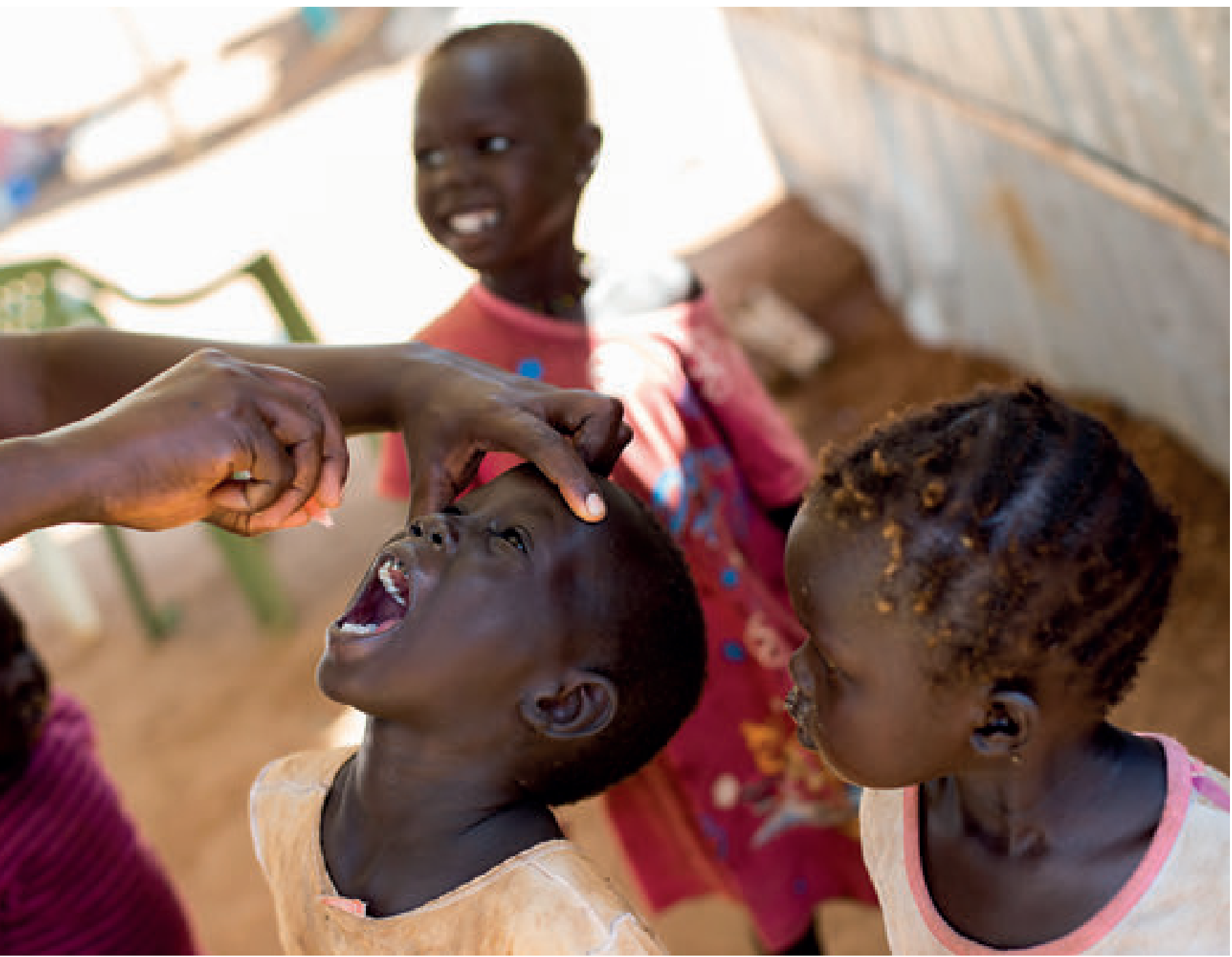

While vaccines, initially discovered in the eighteenth century, have proven their success for a long time in saving lives and eradicating scourges of the past - notably smallpox, and nearly polio - immunizations are challenged and refused in many parts of the world.

2014). To address this pattern of communication chaos, mass media, global health experts, and international development agencies during the crisis urgently called for the development of social and behavior change communication (SBCC) to complement global health efforts to contain the further spread of Ebola (Gurman, 2015).

Communication guides that have been developed and validated by public health leaders, policymakers, and experts to address disease outbreaks in the past are part of the SBCC's evidence base for facilitating effective communication around the current Ebola crisis. The maxims for effective communication on health and risk issues that were initially developed in 1997 for the World Health Organization as part of a consultation to help facilitate effective communication around the mad cow crisis. It has been adapted (see Goldberg, Ratzan, Jacobson, \& Parker, 2015) with input from health communication and health-literacy experts as a useful guide to help experts fight against Ebola and future outbreaks (Ratzan, 1998).

Other areas of infectious disease prevention such as vaccinations also require communication prowess at a centralized, credible, and scientifically-based level. While vaccines, initially discovered in 
the eighteenth century, have proven their succes for a long time in saving lives and eradicating scourges of the past - notably smallpox, and nearly polio immunizations are challenged and refused in many parts of the world.

Today, anti-vaccine activists are organized well, promulgating skepticism with inconsistencies, fallacies and misconceptions aimed at the public and decision makers. The exposure by the British Medical Journal of the fraud in the Wakefield 1998 The Lancet article that purportedly linked autism with vaccines, as well as the preponderance of evidence that has countered, and other «harms» (e.g. thimerosal) should provide exigencies for the health polity to unite and advance interest in learning the scientific facts and generating a commitment to vaccination coverage. There is complexity on why people refuse a proven intervention that has demonstrably enhanced health globally. The scientific, medical and public health establishment continues to provide evidence of the value of immunization.

Nonetheless, even with the proven value of vaccination evidence, vaccine advocacy is difficult. There is no overarching advocacy constituency as is evident in specific disease categories such as HIV, certain cancers and diabetes. Additionally, amongst policymakers and the public there is misunderstanding of the importance of herd immunity, in which vaccination of only a percentage of a population is sufficient to protect the whole population against that disease (Larson, Cooper, Eskola, Katz, \& Ratzan, 2011).

It is clear that the stakes remain high to prevent and respond to future infectious disease challenges. Professor Peter Piot, Director of the London School of Hygiene \& Tropical Medicine and co-discoverer of the Ebola virus said:

\footnotetext{
Major reform of national and global systems to respond to epidemics are not only feasible, but also essential so that we do not witness such depths of suffering, death and social and economic havoc in future epidemics. The AIDS pandemic put global health on the world's agenda. The Ebola crisis in West Africa should now be an equal game changer for how the world prevents and responds to epidemics.
}

(London School of Hygiene \& Tropical Medicine, 2015)

Further, in the Independent Panel report on the Global Response to Ebola, sponsored by the
Harvard Global Health Institute and the London School of Hygiene \& Tropical Medicine, experts suggest the World Health Organization should create a separate unit at the center of the WHO for combating infectious disease. Additionally, the report suggests the WHO should have «[leadership] with the character and capacity to challenge the most powerful governments when necessary to protect public health.» (Moon et al., 2015).

Finally, it is clear that especially in a connected 24/7/365 world, Ebola and vaccines have core challenges of (un)ethical communication. Information from social media and «experts» advance «remarkable» non-evidence-based (read false) claims on vaccines and disease threats (e.g. Ebola) that are easily repeated and packaged to become the omnipotent «they say». James Fenimore Cooper warned of this hazard 180 years ago: "They say" is the monarch of this country, in a social sense. No one asks "who says it", so long as it is believed that "they say it".» (Fenimore Cooper, [1938], 2000).

We should note that «they» also often say that doing the right thing is rarely easy, but doing the easy thing is rarely right. In the case of risk from Ebola (in non-endemic countries) and vaccination, we owe it to the health politic (we are «they») to do the right thing and develop a health-literate population.

\section{HEALTH LITERACY AND NON-COMMUNICABLE DISEASES}

Health literacy began to garner significance late last Century with the publication of Current Bibliographies of Medicine by the National Library of Medicine. In this 2000 publication with 479 citations, a definition emerged which has been integrated into US health care policy: «Health literacy is the degree to which individuals have the capacity to obtain, process, and understand basic health information and services needed to make appropriate health decisions» (Ratzan \& Parker, 2000).

This definition can encompass mobile health information and ehealth technologies. It also addresses health services, which is important because much of what needs to be addressed is how health care is delivered.

For example, Columbia University's Mailman School of Public Health has a course that addresses 


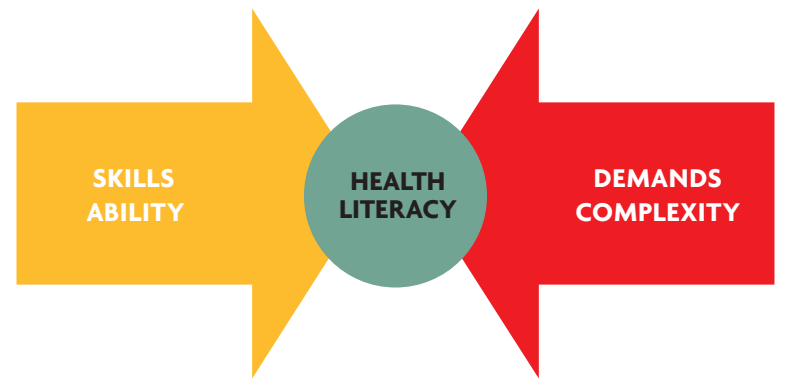

Health literacy requires advancing communication prowess, as well as decreasing the complexity of health information.

Source: Parker (2009). Health literacy. Part 1. The Basics. WHCA Action Guide.

health literacy. Health literacy is also integrated into their Public Health Oath: «I will advance health literacy for all and seek equity and justice for vulnerable populations» (Columbia University Mailman School of Public Health, n.d.). Thus, evolving competencies for 21 st century medical training provides an opportunity for increasing knowledge about health literacy.

In September 2011, a political declaration of the high level meeting of the United Nations General Assembly on the prevention and control of noncommunicable diseases was issued. One of the recommendations reads:

Develop, strengthen and implement as appropriate, multisectoral public policies and action plans to promote health education and health literacy, including through evidence-based education and information strategies and programmes in and out of schools, and through public awareness campaigns.

(United Nations [UN], 2011)

Activities in health literacy abound globally with 33 different published measures including health literacy specific to diabetes, media health, and e-health literacy (Pleasant, 2014). New areas of promise include alcohol health literacy, creating a metric for advancing evidence-based programs and «smarter» social norms that will ultimately reduce harmful use of alcohol.

Online and mobile communication technologies offer scalable, tailored, participatory ways to advance health literacy. Future options may include checklist and scorecard tools that provide widely acceptable, easily accessible, understandable, and actionable health information to patients and consumers of varying levels of economic status and health literacy. Simple interactive scorecards could advance a health competent citizenship that takes action at multiple levels to address chronic, non-communicable diseases, maternal and child mortality, and infectious diseases.
GLOBAL HEALTH REQUIRES MULTISECTORAL ATTENTION

In September 2015, world leaders at the UN agreed on new Sustainable Development Goals entitled Transforming our world: The 2030 agenda for sustainable development. This Agenda is an action plan for people, planet and prosperity. The seventeen Sustainable Development Goals and 169 targets are ambitions designed to stimulate action over the next fifteen years in areas of critical importance for humanity and the planet.

Of course, health - our only common currency on the planet - is featured as Goal 3 «Ensure healthy lives and promote well-being for all at all ages» with excerpts below:

To promote physical and mental health and wellbeing, and to extend life expectancy for all, we must achieve universal health coverage and access to quality health care. No one must be left behind. We commit to accelerating the progress made to date in reducing newborn, child and maternal mortality by ending all such preventable deaths before 2030. We are committed to ensuring universal access to sexual and reproductive health-care services, including for family planning, information and education. We will equally accelerate the pace of progress made in fighting malaria, HIV/AIDS, tuberculosis, hepatitis, Ebola and other communicable diseases and epidemics, including by addressing growing anti-microbial resistance and the problem of unattended diseases affecting developing countries. We are committed to the prevention and treatment of non-communicable diseases, including behavioural, developmental and neurological disorders, which constitute a major challenge for sustainable development.

(UN, 2015)

Other areas of the sustainable development goal indicators include road traffic accidents. As indicated in Indicator 3.6 of the same document: «By 2020, halve the number of global deaths and injuries from Road traffic accidents» (UN, 2015). Traffic accidents are the eighth leading cause of death today and expected to climb to the fifth leading cause of death by 2030, eclipsing diseases such as HIV/AIDS, diabetes and hypertension (WHO, 2013). This large and pressing global health issue also requires multisectoral attention, engagement and communication. In particular, it is important to raise awareness of the issue amongst stakeholders to develop prudent public policy. Currently, only 28 countries (which make up $7 \%$ of the world's population) have adequate laws that address all 


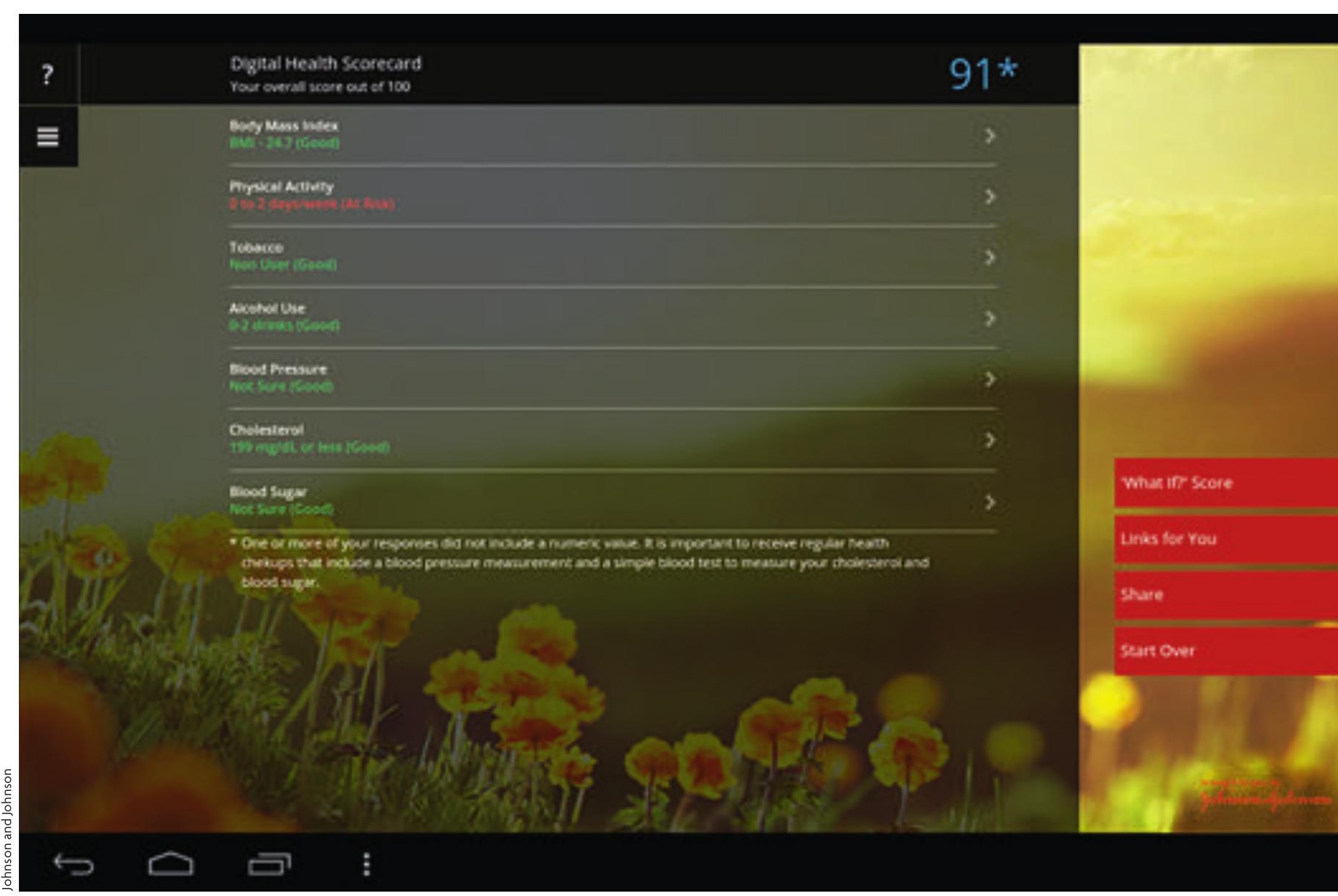

Apps such as the one above allow the users to control from their mobile phones or tablets risk factors such as overweight, tobacco and alcohol. The user's values are shown on the left tab following a red, yellow and green codification. The first red button on the right allows the user to see the possible score after changing the levels of the risk factors.

five risk factors to road traffic death - speed, drink driving, helmets, seat-belts, and child restraints (WHO, 2013).

The final indicator of the SDGs - goal 17 - is entitled: Revitalize the global partnership for sustainable development. It heralds the need to revitalize sustainable development including partnerships between governments, the private sector and civil society. Leadership amongst academia such as the new Columbia Population Health Partnership can help develop inclusive partnerships that the UN strives for based on «principles and values, a shared vision, and shared goals that place people and the planet at the centre, at the global, regional, national and local level.» (UN, n. d.).
For example, an innovative private sector partnership - Together for Safer Roads - was launched at the United Nations with leading multinational CEOs banding together to galvanize multisectoral action (see www.togetherforsaferroads.org). These types of evidence-based innovative approaches with fundamentals of communication and mobilization are key to attain these new Sustainable Development Goals.

The opportunity for health communication to make a difference in advancing global health is broad with ten major opportunities which are evidence, science and theory based: 1) increasing the intended audience's knowledge, awareness and/or behavior related to a health issue; 2) influencing perceptions, beliefs, and attitudes that 
may affect healthy social norms; 3) advancing health literacy, self-efficacy and health system competence; 4) demonstrating, illustrating and diffusing healthy skills and behaviors; 5) reinforcing and educating with knowledge, attitudes, and/or behavior; 6) showing the benefit (economic, social, health etc.) of behavior and social change; 7) advocating position(s), building support and prompting action for prudent health and public policy; 8) increasing appropriate demand and/or support for health promotion and health services; 9) advancing understanding of risk/benefits, risk-risk including refuting myths and misconceptions; and 10) strengthening effective educational, professional, governmental and organizational interventions.

As health communicators, we need to help interpret and communicate the evidence from a multisectoral perspective, discriminate between values and try to do no harm. In some cases this may mean doing nothing and supporting the status quo, in others it will require extensive evidence-, theory-, and science-based approaches to support long term health habits with societal norms that advance a healthier, happier and better world. The work of the Innovation Working Group, developments in the field of health communication and health literacy, and scaling pluridisciplinary approaches from global to local levels, will make for a better world for all of us today and for the future generations that follow. (๑)

\section{REFERENCES}

Columbia University Mailman School of Public Health. (n. d.). Public health oath. Retrieved from https://www.mailman.columbia.edu/about/ mission-history/public-health-oath

Fenimore Cooper, J. (2000). The American democrat and other political writings. Washington: Regnery Publishing.

Gawande, A. (2010). The checklist manifesto: How to get things right. New York: Metropolitan Books.

Goldberg, A., Ratzan, S. C., Jacobson, K. L., \& Parker, R. M. (2015). Adressing Ebola and other outbreaks: A communication checklist for global health leaders, policemakers, and practitioners. Journal of Health Communication, 20, 121-122. doi: 10.1080/10810730.2015.1007762 Grad, F. P. (2002). The preamble of the Constitution of the World Health Organization. Bulletin of the World Health Organization, 80, 981-984. Gurman, T. A. (2015). Back to basics: Improving the conceptualization and operationalization of programmatic exposure in social and behavior change communication through conceptual models. Journal of Health Communication, 20(1), 1-3. doi: 10.1080/10810730.2015.1001699

Larson, H. J., Cooper. L. Z., Eskola, J., Katz, S. L., \& Ratzan, S. C. (2011). Addressing the vaccine confidence gap. The Lancet, 378(9790), 526-535. doi: 10.1016/S0140-6736(11)60678-8
London School of Hygiene \& Tropical Medicine. (2015, 23 November). Independent panel of global experts calls for critical reforms to prevent future pandemics. Retrieved from http://www.lshtm.ac.uk/newsevents/ news/2015/ebola_report.html

Moon, S., Sridhar, D., Pate, M. A., Jha, A. K., Cinton, Ch., Delaunay, S., ... Piot, P. (2015). Will Ebola change the game? Ten essential reforms before the next pandemic. The report of the Harvard-LSHTM independent panel on the global response to Ebola. The Lancet, 386, 2204-2221. doi: 10.1016/S0140-6736(15)00946-0

Pleasant, A. (2014). Advancing health literacy measurement: A pathway to better health and health system performance. Journal of Health Communication, 19(12), 1481-1496. doi: 10.1080/10810730.2014.954083 Pronovost, P., Needham, D., Berenholtz, S., Sinopoli, D., Chu, H., Cosgrove, S., ... Goeschel, C. (2006). An intervention to decrease catheter-related bloodstream infections in the ICU. New England Journal of Medicine, 355(26), 2725-2732. doi: 10.1056/NEJMoa061115

Ratzan, S. C. (1998). Mad cow crisis: Health and the public good. London: UCL Press.

Ratzan, S., \& Parker, R. M. (2000). Introduction. In C. R. Selden, M. Zorn, S. Ratzan, \& R. M. Parker (Eds.), National library of medicine current bibliographies in medicine: Health literacy. Bethesda, MD: National Institutes of Health, U.S Department of Health and Human Services. Ratzan, S. C., \& Moritsugu, K. P. (2014). Ebola crisis - communication chaos we can avoid. Journal of Health Communication, 19(11), 1213-1215. doi: $10.1080 / 10810730.2014 .977680$

Spector, J. M., \& Ratzan, S. C. (Eds.). (2012). Checklists for the last kilometer: Innovative strategies to ensure that life-saving commodities and information reach women and newborns at the moment of care. Report for Innovation Working Group. Retrieved from http://www. everywomaneverychild.org/images/ReportlChecklists.pdf

The Lancet. (2012). Technologies for global health. The Lancet, 380(9840), 447. doi: 10.1016/S0140-6736(12)61273-2

United Nations. (n.d.). Goal 17: Revitalize the global partnership for sustainable development. Retrieved from http://www.un.org/ sustainabledevelopment/globalpartnerships

United Nations. (2011). Political declaration of the high-level meeting of the General Assembly on the prevention and control of non-communicable diseases. Retrieved from http://www.un.org/ga/search/view_doc. asp?symbol=A/66/L.1

United Nations. (2015). Transforming our world: The 2030 agenda for sustainable development. Retrieved from https://sustainabledevelopment. un.org/post2015/transformingourworld

United Nations Population Fund. (2012). UN commission on life-saving commodities for women and children. Commisioner's report. Retrieved from http://www.unfpa.org/sites/default/files/pub-pdf/Final\%20UN\%20 Commission\%20Report_14sept2012.pdf

World Health Organization. (2010). Every women, every child: Investing in our common future. Innovation Working Group Report. Retrieved from http://www.who.int/pmnch/activities/jointactionplan/100922_2_investing. pdf

World Health Organization. (2013). Global status report on road safety 2013. Retrieved from http://www.who.int/violence_injury_prevention/ road_safety_status/2013/en

Scott C. Ratzan. M.D., M.P.A., M.A. Adjunct Professor at the Department of Sociomedical Sciences at Columbia University Mailman School of Public Health (USA), Editor-in-Chief of the Journal of Health Communication: International Perspectives, and Vice-President of Global Corporate Affairs for ABInBev based in New York. 